\title{
FlexPro MD, a Mixture of Krill Oil, Astaxanthin, and Hyaluronic Acid, Suppresses Lipopolysaccharide-Induced Inflammatory Cytokine Production Through Inhibition of NF- $\kappa$ B
}

\author{
Doo Ri Park, ${ }^{1,2, *}$ Ryeojin Ko, ${ }^{1,2}$ * Suk Hyung Kwon, ${ }^{3}$ Bokkee Min, ${ }^{3}$ Seong Ho Yun, \\ Manh Heun Kim, John Minatelli, Stephen Hill, and Soo Young Lee ${ }^{1,2}$ \\ ${ }^{1}$ Department of Life Science, Ewha Womans University, Seoul, Korea. \\ ${ }^{2}$ The Research Center for Cellular Homeostasis, Ewha Womans University, Seoul, Korea. \\ ${ }^{3}$ Novarex Co., Ltd., Cheongju, Korea. \\ ${ }^{4}$ US Nutraceuticals, L.L.C. d/b/a Valensa International, Eustis, Florida, USA.
}

\begin{abstract}
FlexPro MD ${ }^{\circledR}$ (FP-MD), a novel multi-ingredient dietary supplement formulation, has been demonstrated to relieve knee joint pain in humans. However, the mechanisms of action responsible for the activity of FP-MD have not been elucidated. In this study, we show the anti-inflammatory effects of FP-MD in RAW264.7 macrophage cells and mice challenged with lipopolysaccharide (LPS). FP-MD significantly inhibited the mRNA levels of pro-inflammatory cytokines, including interleukin-6 (IL-6), tumor necrosis factor- $\alpha$ (TNF- $\alpha$ ), and IL-1 $\beta$. In contrast, it elevated the mRNA levels of anti-inflammatory cytokine IL-10 in LPS-stimulated RAW264.7 cells. FP-MD markedly reduced LPS-induced phosphorylation levels of nuclear factor- $\kappa \mathrm{B}(\mathrm{NF}-\kappa \mathrm{B})$ p 65 and inhibitor of $\kappa \mathrm{B}-\alpha(\mathrm{I} \kappa \mathrm{B}-\alpha)$. Importantly, the anti-inflammatory effects of FP-MD were demonstrated in mice with LPS-induced inflammatory arthritis in which FP-MD significantly reduced the expression levels of proinflammatory cytokines and inflammatory markers. Thus, this study suggests that FP-MD has anti-inflammatory effects by inhibiting NF- $\kappa$ B that may offer a molecular basis for its pain relief property.
\end{abstract}

KEYWORDS: • astaxanthin $\bullet$ cytokines $\bullet N F-\kappa B$

\section{INTRODUCTION}

$\mathbf{O}$ STEOARTHRITIS (OA), the most prevalent type of arthritis, is characterized by degradation of the articular cartilage that is caused by many risk factors such as mechanical stress and metabolic or genetic factors. ${ }^{1,2}$ There is no cure for OA. However, many therapies are available to help relieve the pain and inflammation, including steroids, anti-inflammatory patches, COX-2-specific nonsteroidal anti-inflammatory drugs, and hyaluronic acid (HA) injections into the joint to increase flexibility. ${ }^{3-6}$ The most well-known dietary supplement for individuals with $\mathrm{OA}$ is glucosamine-chondroitin sulfate. However, glucosamine-chondroitin sulfate can cause stomach upset, constipation, diarrhea, headache, and rash. ${ }^{7,8}$

There are two main categories of polyunsaturated fatty acids: omega- 3 and omega- 6 fatty acids. Omega- 3 fatty acids in fish oil can inhibit the production of both eicosanoid and cytokine inflammatory mediators, thus having the potential to

*These authors contributed equally to this work.

Manuscript received 29 June 2016. Revision accepted 15 November 2016.

Address correspondence to: Soo Young Lee, PhD, Ewhayeodae-gil 52, Department of Life Science, Ewha Womans University, Seoul 03760, Korea, E-mail: leesy@ewha.ac.kr be used as adjunctive therapy for various inflammatory diseases, including arthritis, atopic dermatitis, and cardiovascular disease. ${ }^{9-13}$ Krill oil (KO) extracted from Antarctic Krill (Euphausia superba) is a rich source for omega-3 fatty acids, including eicosapentaenoic acid (EPA) and docosahexaenoic acid (DHA). Recent studies have demonstrated that EPA and DHA can decrease IL- $1 \beta$-mediated cartilage degradation and inflammatory markers such as matrix metalloproteinase (MMP)-3, MMP-13, a disintegrin, and metalloproteinase with thrombospondin motifs 4 (ADAMTS-4), ADAMTS-5, and COX-2 in osteocytes. ${ }^{14-17}$

Astaxanthin (AST), a member of the xanthophyll family of hydroxycarotenoids, has been found in various microorganisms, marine animals, and seafood with antioxidant and anti-inflammatory activity, as well as pro-inflammatory cytokine-suppressing activity. ${ }^{18-21}$ AST can remove single oxygen atoms and protect organs from damage by suppressing oxidative damage of DNA and enhancing immune response in young and female subjects. ${ }^{22}$ In addition, AST ester and carotenoids from Hematococcus have protective effects against gastric lesion in ethanol-induced gastric ulcer of rat. ${ }^{23}$ AST reduces MMP expression in human chondrocytes and is known to be safe for human consumption. ${ }^{24,25}$ 
HA is a natural molecule, found in connective tissue, skin, and neuronal tissue. It plays a crucial role in all regions of the joint. It is actively synthesized by synoviocytes and complexed with proteoglycans in the cartilage.$^{26} \mathrm{HA}$ is essential for maintaining the structural and functional characteristics such as keeping flexibility of joints and protecting against the wearing down of osteocyte and cartilage. ${ }^{27} \mathrm{HA}$ has been widely used in therapies for OA pain. ${ }^{6}$ Recent studies have demonstrated that HA can modify symptoms and relieve joint pain in $\mathrm{OA}^{28-30}$

FlexPro MD ${ }^{\circledR}$ (FP-MD), a novel and patented joint healthcare supplement consisting of KO, AST, and HA, has shown remarkable knee joint pain relief in subjects suffering from chronic mild to moderate knee joint pain in an unpublished double-blinded placebo controlled study in humans conducted in the USA. ${ }^{31,32}$ The objective of this study was to explore the mechanisms of action responsible for the activity of FP-MD in the LPS-induced inflammation of macrophage cells and in a mouse model.

\section{MATERIALS AND METHODS}

\section{Animals}

Male C57BL/6 mice (8-10-week-old) were used for the experimental arthritis study. All animal experiments were maintained under specific pathogen-free conditions with a temperature of $22^{\circ} \mathrm{C} \pm 1{ }^{\circ} \mathrm{C}$, humidity at $55 \% \pm 10 \%$, and a 12 -h light/12-h dark cycle. Experiments were performed in accordance with the guidelines of the Institutional Animal Care and Use Committees of Ewha Womans University (15-061).

\section{Preparation of FP-MD}

FP-MD, a multi-ingredient dietary supplement formula consisting of $321 \mathrm{mg} \mathrm{KO}, 30 \mathrm{mg} \mathrm{HA}$, and $2 \mathrm{mg}$ AST, was prepared as reported previously ${ }^{31,32}$ and stored at room temperature until use.

\section{LPS-induced arthritis model}

The LPS-induced arthritis model was performed as described previously. ${ }^{33,34}$ Briefly, mice were divided into the following five groups ( $n=5 /$ group): (1) normal untreated group, (2) LPS induced-arthritis group as the negative control, (3) indomethacin $(1 \mathrm{mg} / \mathrm{kg})$ treatment group as the positive control, (4) FP-MD at $33 \mathrm{mg} / \mathrm{kg}$ test group, and (5) FP-MD at $67 \mathrm{mg} / \mathrm{kg}$ test group. On day 0 , indomethacin or FP-MD was fed orally to mice at 2-day intervals for 2 weeks before injecting LPS (10 $\mu \mathrm{g} / \mathrm{mouse}$; Sigma, St. Louis, MO) into mouse intra-articular knee. LPS was injected one more time at 7 days post first injection. As a control for LPS, phosphate-buffered saline (PBS) was injected. Indomethacin and FP-MD were further administered orally at 2-day intervals for 2 weeks. Animals in the LPS group were administered with PBS until the end of the experiments. Mice were sacrificed on day 28 , and knee joint tissues were collected for cytokine analysis.

\section{Cell culture}

RAW264.7 cells were maintained in DMEM (HyClone, Logan, UT) supplemented with $10 \%$ fetal bovine serum (FBS; HyClone) and $100 \mathrm{U} / \mathrm{mL}$ penicillin/streptomycin at $37^{\circ} \mathrm{C}$ with $5 \% \mathrm{CO}_{2}$. For inflammatory cytokine expression, cells were preincubated with or without $10-100 \mu \mathrm{g} / \mathrm{mL}$ FP-MD for $1 \mathrm{~h}$ followed by stimulation with or without $100 \mathrm{ng} / \mathrm{mL}$ LPS for $2 \mathrm{~h}$. For Western blot analysis, cells were preincubated with or without DMSO and $100 \mu \mathrm{g} / \mathrm{mL}$ FP-MD for $1 \mathrm{~h}$ followed by stimulation with or without $1 \mu \mathrm{g} / \mathrm{mL}$ LPS for $5 \mathrm{~min}$.

\section{Real-time PCR analysis}

Total RNAs were isolated from RAW264.7 cells or knee joint tissues of LPS-induced arthritis model mice using RNA Mini Kit (Life Technologies, Carlsbad, CA). They were reverse transcribed to complementary DNA using SuperScript cDNA Synthesis Kit (Invitrogen, Carlsbad, CA) following the manufacturer's instructions. Quantitative PCR (qPCR) was performed on an ABI 7300 real-time PCR machine (Applied Biosystems, Foster City, CA) using KAPA SYBR Green FAST qPCR Kit (Kapa Biosystems, Boston, MA) to determine the levels of mRNAs. Samples were analyzed in triplicates. Expression levels were normalized to the mRNA expression level of $\beta$-actin. Primer sequences used in qPCR are listed in Table 1.

\section{Immunoblot analysis}

Cells were extracted with lysis buffer $(50 \mathrm{mM}$ Tris-HCl, $\mathrm{pH} 8.0,150 \mathrm{mM} \mathrm{NaCl}, 0.5 \%$ deoxycholate acid, and $1 \%$

Table 1. Primers Used for Real-Time PCR

\begin{tabular}{cl}
\hline Gene & \multicolumn{1}{c}{ Sequence $\left(5^{\prime} \rightarrow 3^{\prime}\right)$} \\
\hline$\beta$-actin & \\
$\mathrm{f}$ & TGGAATCCTGTGGCATCCATGAAAC \\
$\mathrm{r}$ & TAAAACGCAGCTCAGTAACAGTCCG \\
$\mathrm{IL}-6$ & GAGGATACCACTCCCAACAGACC \\
$\mathrm{f}$ & AAGTGCATCATCGTTGTTCATACA \\
$\mathrm{r}$ & \\
$\mathrm{TNF}-\alpha$ & TCCCAGGTTCTCTTCAAGGGA \\
$\mathrm{f}$ & GGTGAGGAGCACGTAGTCGG \\
$\mathrm{r}$ & \\
$\mathrm{IL}-1 \beta$ & CACAGCAGCACATCAACAAG \\
$\mathrm{f}$ & GTGCTCATGTCCTCATCCTG \\
$\mathrm{r}$ & \\
$\mathrm{IL}-10$ & GGTTGCCAAGCCTTATCGGA \\
$\mathrm{f}$ & ACCTGCTCCACTGCCTTGCT \\
$\mathrm{r}$ & \\
$\mathrm{MMP} 1$ & TGTTTATTGTTGCTGCCCAT \\
$\mathrm{f}$ & CCTTGAACGTCATCATCAGG \\
$\mathrm{r}$ & \\
$\mathrm{MMP} 2$ & GTGCGACCACAACCAACTAC \\
$\mathrm{f}$ & CTCCAGGGTCCTGAAGAGTGT \\
$\mathrm{r}$ & \\
iNOS & TTCATGAAGCACATGCAGAA \\
$\mathrm{f}$ & ACATCTCCTGGTGGAACACA \\
$\mathrm{r}$ & \\
$\mathrm{COX2}$ & AGAACCTGCAGTTTGCTGTG \\
$\mathrm{f}$ & GCTCCTGCTTGAGTATGTCG \\
$\mathrm{r}$ & \\
\hline
\end{tabular}


NP-40) containing protease and phosphatase inhibitors. Whole cell lysates were separated by sodium dodecyl sulfatepolyacrylamide gel electrophoresis and transferred to PVDF membranes (Millipore, Billerica, MA). Membranes were immune reacted with antibodies conjugated to horseradish peroxidase. Antibodies against NF- $\kappa \mathrm{B}-\mathrm{p} 65$, phosphorylated (p)-p65, p-I $\kappa \mathrm{B}-\alpha$, extracellular signal-regulated kinase (ERK), p-ERK, p38 MAPK, p-p38 MAPK, c-Jun N-terminal kinase (JNK), and p-JNK were purchased from Cell Signaling Technology (Danvers, MA). Glyceraldehyde-3-phosphate dehydrogenase (GAPDH; Santa Cruz Biotechnologies, Santa Cruz, CA) was used as loading controls.

\section{Statistical analysis}

All data were expressed as the mean \pm standard deviation from at least three independent experiments. Differences between groups were evaluated with Student's $t$-test. Statistical significance was considered when $P$ value was less than .05 .

\section{RESULTS}

\section{FP-MD regulates LPS-induced inflammatory cytokine expression.}

Previous studies have reported that LPS is a potent inducer of inflammatory response, including the production of pro- and anti-inflammatory cytokines. ${ }^{35,36}$ To investigate the involvement of FP-MD in the regulation of inflammatory responses, we determined the mRNA levels of LPS-induced inflammatory cytokines in murine macrophage RAW264.7 cells by real-time PCR. As shown in Figure 1A-C, the mRNA levels of pro-inflammatory cytokines, including interleukin-6 (IL-6), tumor necrosis factor- $\alpha$ (TNF- $\alpha$ ), and IL- $1 \beta$, were significantly increased in LPS-stimulated cells compared to those in unstimulated cells. Cells treated with FP-MD had significantly reduced the mRNA levels of IL-6, TNF- $\alpha$, and IL- $1 \beta$ in a dose-dependent manner compared to LPS-stimulated cells. In addition, the mRNA levels of antiinflammatory cytokine IL-10 in LPS-stimulated cells were slightly higher compared to that in unstimulated cells (Fig. 1D). Interestingly, cells treated with LPS and FP-MD had markedly elevated IL-10 mRNA level compared to cells treated by LPS only. These results indicate that FP-MD can reciprocally regulate the production of pro- and antiinflammatory cytokines stimulated by LPS.

\section{FP-MD inhibits LPS-induced NF- $\kappa B$ activation}

Nuclear factor- $\kappa \mathrm{B}(\mathrm{NF}-\kappa \mathrm{B})$ and mitogen-activated protein kinases (MAPKs) signaling pathways are important for LPSinduced inflammatory cytokine expression. ${ }^{37}$ To investigate whether FP-MD could regulate NF- $\kappa$ B and MAPK activation,
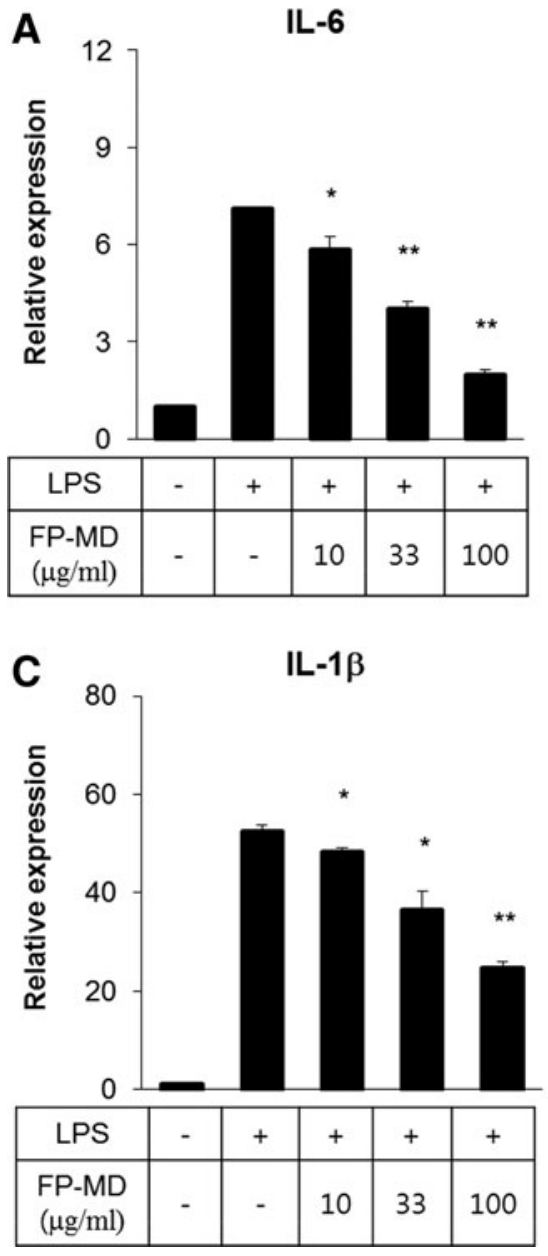
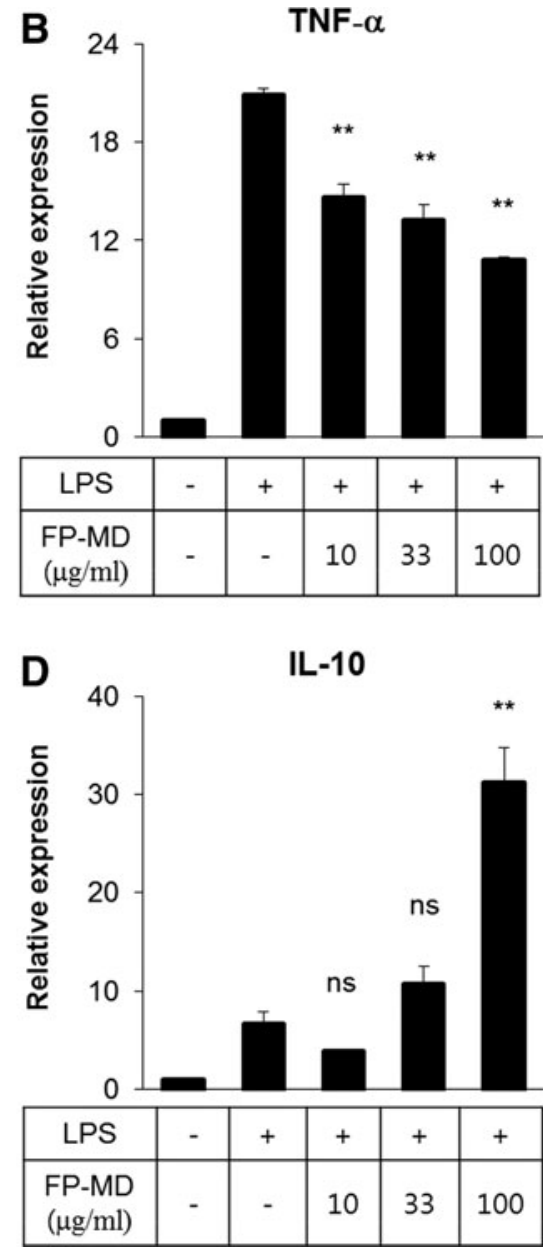

FIG. 1. FP-MD regulates LPS-induced cytokine expression in RAW264.7 cells. RAW264.7 cells were preincubated with or without $10-100 \mu \mathrm{g} / \mathrm{mL}$ FP-MD for $1 \mathrm{~h}$ followed by stimulation with or without $100 \mathrm{ng} / \mathrm{mL}$ LPS for $2 \mathrm{~h}$. Levels of IL-6 (A), TNF- $\alpha$ (B), IL-1 $\beta$ (C), and IL-10 (D) were determined by real-time PCR. Their expression levels were normalized to the expression level of $\beta$-actin. $* P<.05, * * P<.01$, significantly different from the values obtained for cells treated with LPS in the absence of indomethacin or FP-MD. IL, interleukin; LPS, lipopolysaccharide; TNF- $\alpha$, tumor necrosis factor- $\alpha$. 
A
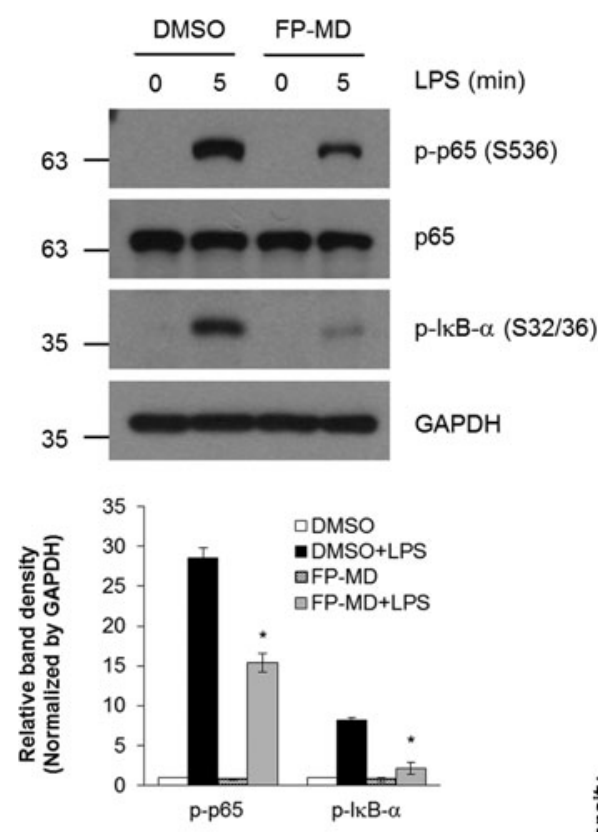

B

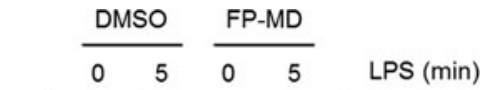

$$
48
$$
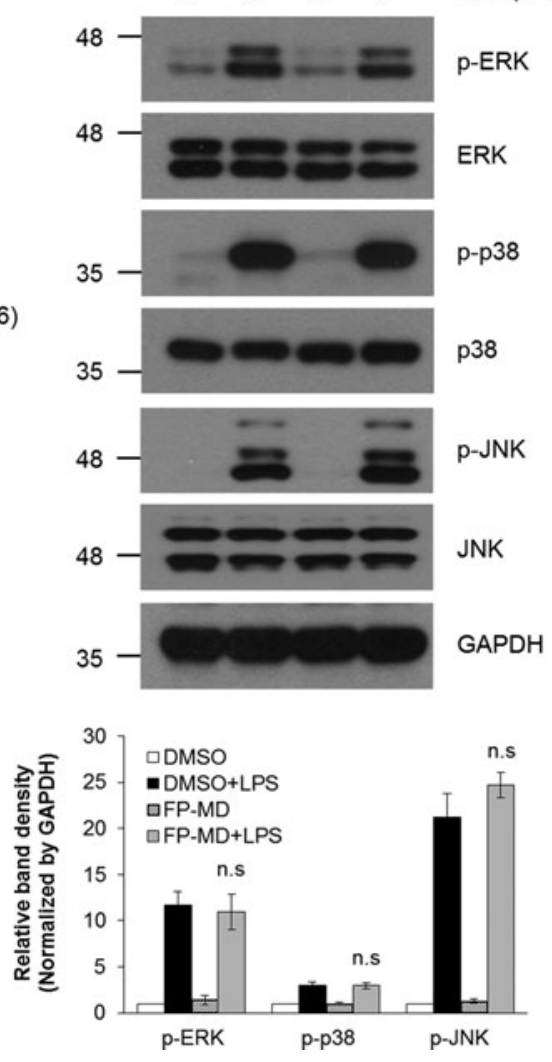

\section{A}

IL-6

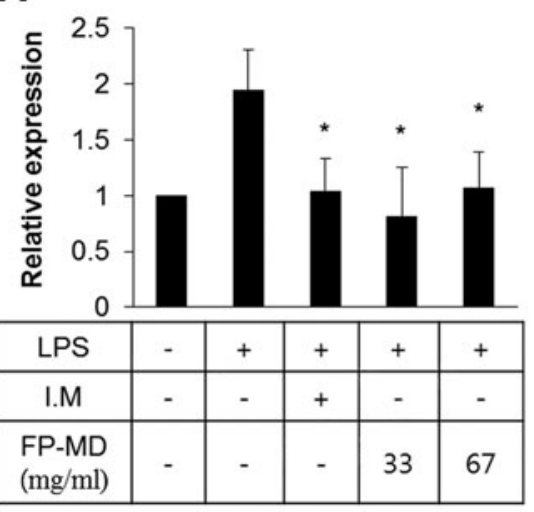

C

IL-1 $\beta$

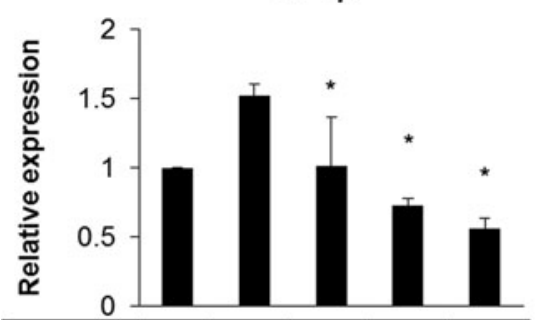

\begin{tabular}{|c|c|c|c|c|c|}
\hline LPS & - & + & + & + & + \\
\hline I.M & - & - & + & - & - \\
\hline $\begin{array}{l}\text { FP-MD } \\
(\mathrm{mg} / \mathrm{ml})\end{array}$ & - & - & - & 33 & 67 \\
\hline
\end{tabular}

B

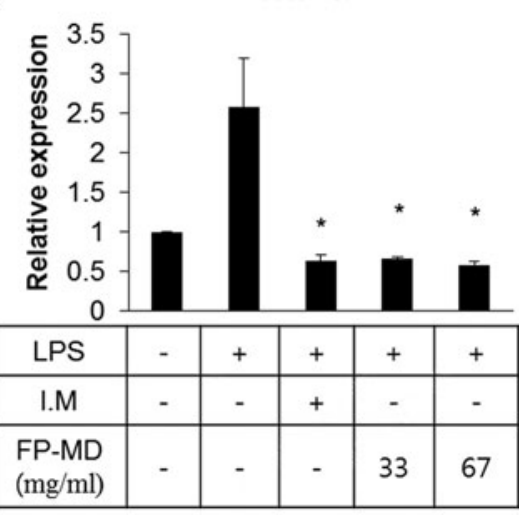

D

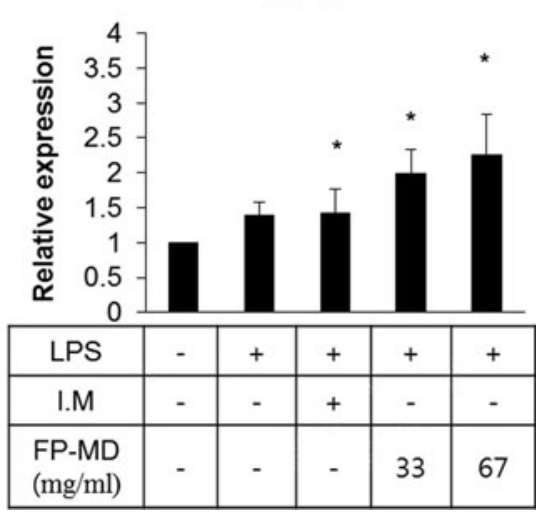

FIG. 2. FP-MD regulates LPS-induced NF- $\kappa$ B activation in RAW264.7 cells. RAW264.7 cells were preincubated with or without DMSO and $100 \mu \mathrm{g} / \mathrm{mL}$ FP-MD for $1 \mathrm{~h}$ followed by stimulation with or without $1 \mu \mathrm{g} / \mathrm{mL}$ LPS for $5 \mathrm{~min}$. The phosphorylation levels of NF- $\kappa \mathrm{B}$ p 65 and $\mathrm{I} \kappa \mathrm{B}-\alpha$ (A) and MAPKs, such as ERK, p38, and JNK (B), were determined by immunoblotting. The ratios $\mathrm{p}$ p65 to total p65 and p-I $\kappa \mathrm{B}-\alpha$ to GAPDH (A), as well as p-ERK to total ERK, p-p38 to total p38, and p-JNK to total p38 (B), were quantified from three independent experiments. $* P<.05$. ERK, extracellular signal-regulated kinase; GAPDH, glyceraldehyde 3-phosphate dehydrogenase; JNK, c-Jun N-terminal kinase; MAPK, mitogenactivated protein kinase; NF- $\kappa \mathrm{B}$, nuclear factor$\kappa \mathrm{B} ;$ n.s., not significant.
FIG. 3. FP-MD modulates inflammatory cytokine expression in inflammatory arthritis. Indomethacin $(1 \mathrm{mg} / \mathrm{kg})$ or FP-MD 33 or $67 \mathrm{mg} / \mathrm{kg}$ was orally administrated at 2-day intervals for 15 days before injecting LPS. At 2 days post LPS injection, indomethacin and FP-MD were further administered orally at 2-day intervals for 2 weeks. Levels of IL-6 (A), TNF- $\alpha$ (B), IL-1 $\beta$ (C), and IL-10 (D) mRNAs were determined by real-time PCR. Their expression levels were normalized to that of $\beta$-actin. Values are expressed as mean \pm SD. $n=5$. $* P<.05$ compared to that in the LPS group. IM, indomethacin. SD, standard deviation. 

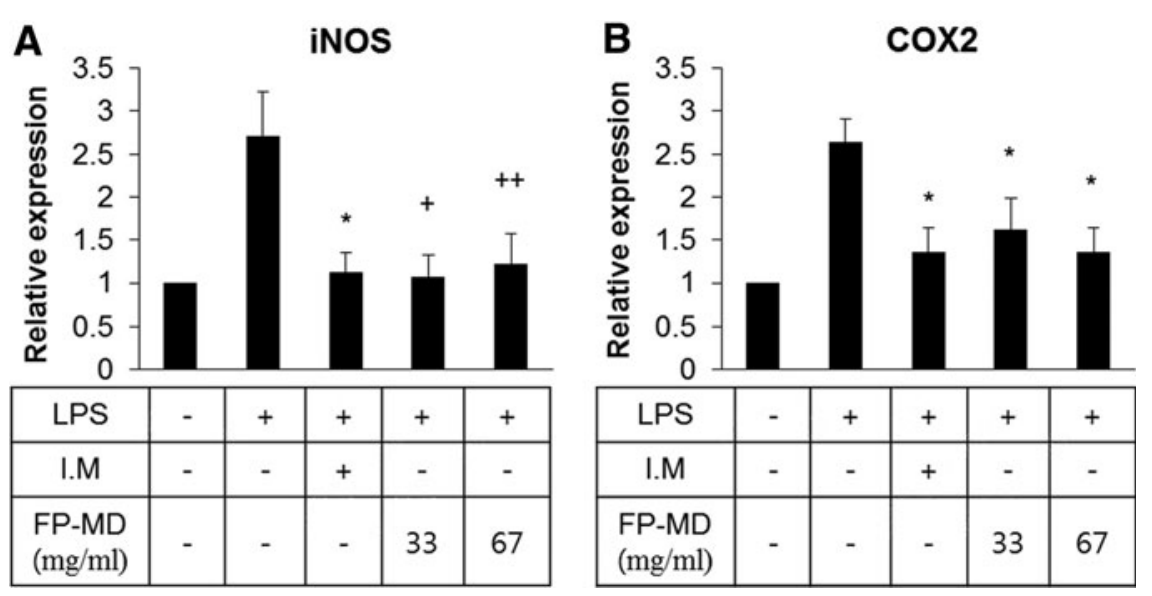

FIG. 4. FP-MD inhibits the expression levels of NF- $\kappa \mathrm{B}$-dependent inflammatory markers in inflammatory arthritis. Levels of iNOS (A) and COX2 (B) mRNAs were determined by real-time PCR. Their expression levels were normalized to that of $\beta$-actin. Values are expressed as mean \pm SD. $n=5 . * P<.05,{ }^{+} P<.01,{ }^{+} P<.001$ compared to that in the LPS group. we examined LPS-induced phosphorylation levels of NF- $\kappa \mathrm{B}$ p65, I $\kappa$ B- $\alpha$, ERK, p38, and JNK in RAW264.7 cells by immunoblotting. As shown in Figure 2A, FP-MD markedly reduced LPS-induced phosphorylation levels of NF- $\kappa \mathrm{B}$ p 65 and $\mathrm{I} \kappa \mathrm{B}-\alpha$ compared to DMSO control. However, there were no significant differences in LPS-induced phosphorylation levels of ERK, p38, or JNK between FP-MD treatment and DMSO control (Fig. 2B). These data suggest that FP-MD can specifically inhibit the NF- $\kappa \mathrm{B}$ signaling pathway induced by LPS.

\section{Effect of FP-MD on inflammatory cytokine expression in mouse knee joint tissues}

Inflammation in arthritis induces expression of proinflammatory cytokines, such as IL-6, TNF- $\alpha$, and L- $1 \beta$, as well as anti-inflammatory cytokine IL- $10 .^{38}$ To investigate the effect of FP-MD on the expression of inflammatory cytokines in the LPS-induced arthritis model, mice were sacrificed followed by isolation of mRNAs from knee joints. Quantitative real-time PCR analysis indicated that the mRNA levels of proinflammatory cytokines, including IL-6, TNF- $\alpha$, and IL- $1 \beta$, were markedly decreased in FP-MD-administrated mice compared with those in LPS-administrated mice (Fig. 3A-C). In contrast, FP-MD administration significantly increased the expression levels of IL-10 mRNA (Fig. 3D). These results suggest that FP-MD can act as a modulator of inflammation in knee joints.

\section{FP-MD inhibits $N F-\kappa B$-dependent iNOS and $C O X-2$ expression}

During inflammation, large amounts of the proinflammatory mediators such as $\mathrm{NO}$ and $\mathrm{PGE}_{2}$ are generated by iNOS and COX-2. It has been well established that iNOS and COX-2 are expressed in response to LPS through NF- $\kappa \mathrm{B}-$ dependent pathway. The expression levels of iNOS and COX-2 have been used as markers of NF- $\kappa$ B activation. ${ }^{39,40}$ To investigate the effect of FP-MD on NF- $\kappa \mathrm{B}$ activation, mRNA expression levels of iNOS and COX-2 in knee joints were measured by quantitative real-time PCR. As shown in Figure 4, FP-MD administration significantly decreased the mRNA levels of iNOS and COX2. These results suggest that FP-MD might be able to inhibit NF- $\kappa$ B-dependent pathway in inflammatory knee joints.

\section{FP-MD attenuates MMP1 and MMP2 expression}

Irreversible destruction to the cartilage, tendon, and bone of the synovial joints is the hallmark of both rheumatoid arthritis (RA) and osteoarthritis. ${ }^{41}$ It has been reported that the expression levels of metalloproteinases such as MMP1 and MMP2 are elevated in arthritis. These enzymes can degrade noncollagen matrix components of the joints. Therefore, we investigated whether FP-MD could inhibit MMP1 and MMP2 expression in knee joints. The mRNA
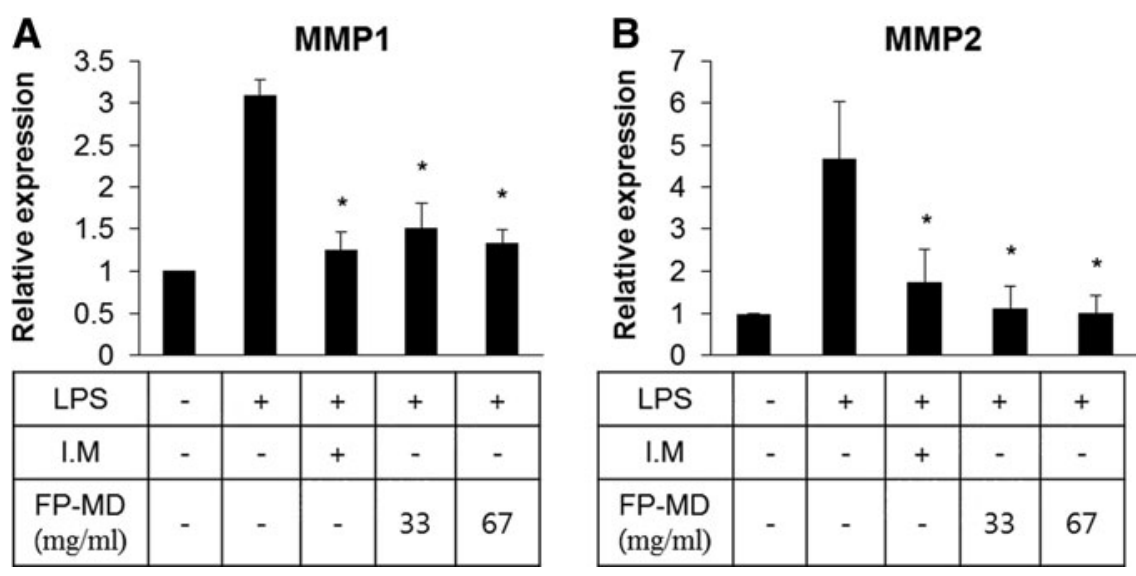

FIG. 5. FP-MD inhibits the expression levels of MMP1 and MMP2 in inflammatory arthritis. Levels of MMP1 (A) and MMP2 (B) mRNAs were determined by real-time PCR. Their expression levels were normalized to that of $\beta$ actin. Values are expressed as mean \pm SD. $n=5$. $* P<.05$ compared to that in the LPS group. 
levels of MMP1 and MMP2 in knees joints were measured by quantitative real-time PCR. As shown in Figure 5, FPMD significantly decreased the expression levels of MMP1 and MMP2, suggesting that FP-MD can effectively prevent degradation of noncollagen matrix components in inflammatory arthritis.

\section{DISCUSSION}

RA and OA are joint diseases with different pathophysiological mechanisms. However, they have common clinical characteristics such as joint pain, functional disability, and structural damage. The hallmarks of RA and OA are bone erosions and osteophytes, respectively. Both RA and OA display joint space narrowing, reflecting cartilage loss. Another common characteristic of the two diseases is the presence of inflammation in the majority of affected individuals. While the role of inflammation in the pathogenesis of RA has been established previously, its possible role in OA has only been uncovered recently. A number of studies have shown the association between synovial inflammation and pain, as well as radiographic progression, thus establishing the critical role of inflammation in OA. ${ }^{42,43}$ Although there is no diet or food supplement to cure arthritis, certain food supplements have been shown to be able to fight inflammation and boost the immune system. ${ }^{44,45}$ Therefore, adding these food supplements might be able to attenuate the symptoms of arthritis.

In this study, we showed that FP-MD, a mixture of KO, AST, and HA, significantly reduced the expression levels of pro-inflammatory cytokines such as IL- $1 \beta$, IL- 6 , and TNF- $\alpha$, but increased the expression levels of anti-inflammatory cytokine IL-10 both in vitro and in vivo. ${ }^{46-48}$ Mechanistically, FP-MD markedly decreased LPS-induced phosphorylation levels of NF- $\kappa$ B p 65 and $\mathrm{I} \kappa \mathrm{B}-\alpha$. Since NF- $\kappa \mathrm{B}$ has long been considered as a prototypical pro-inflammatory signal whose activation is largely based on pro-inflammatory cytokines such as IL- $1 \beta$ and TNF- $\alpha,{ }^{49-52}$ the inhibitory effects of FP-MD on the expression of pro-inflammatory cytokines might be due to suppression to the NF- $\kappa \mathrm{B}$. Previous studies have suggested that the activation of COX-2 pathway is involved in the pathogenesis of RA and OA. ${ }^{53,54}$ Accordingly, inhibition of COX-2 expression by FP-MD strongly indicates that FP-MD might have a beneficial effect on inflammatory arthritis. In addition, MMPs have predominant roles in RA and OA because they are rate limiting factors in the process of collagen degradation. ${ }^{34}$ Since FP-MD can inhibit the production of MMPs at the transcriptional level, FP-MD might be used as anti-inflammatory supplements for arthritis.

Indomethacin is a nonsteroidal anti-inflammatory drug used to treat mild to moderate acute pain. It is also used to relieve symptoms of RA and OA. ${ }^{55,56}$ FP-MD has shown similar efficacy compared to indomethacin in inhibiting the expression levels of pro-inflammatory cytokines and COX-2, as well as MMPs, in LPS-induced arthritis mice. Such inhibitory efficacy of FP-MD supports its effectiveness for attenuating inflammation in arthritis. Our study further confirms the extraordinary pain relief results of an unpub- lished double-blinded placebo controlled human clinical trial of FP-MD compared to an added positive control arm containing glucosamine/chondroitin conducted in the USA in subjects suffering from mild to moderate knee pain. ${ }^{31,32}$

\section{ACKNOWLEDGMENT}

This study was funded by US Nutraceuticals, LLC and Novarex, Ltd.

\section{AUTHOR DISCLOSURE STATEMENT}

S.Y.L. received research funding from Novarex, Ltd., which is related to the research described in this article. S.H.K., B.M., S.H.Y., and M.H.K. are the employees of Novarex, Ltd. J.M. and S.H. are employees of US Nutraceuticals, LLC.

\section{REFERENCES}

1. Lawrence RC, Helmick CG, Arnett FC, et al.: Estimates of the prevalence of arthritis and selected musculoskeletal disorders in the United States. Arthritis Rheum 1998;41:778-799.

2. Antony B, Jones G, Jin X, Ding C: Do early life factors affect the development of knee osteoarthritis in later life: A narrative review. Arthritis Res Ther 2016;18:202.

3. Kingsbury SR, Hensor EM, Walsh CA, Hochberg MC, Conaghan PG: How do people with knee osteoarthritis use osteoarthritis pain medications and does this change over time? Data from the Osteoarthritis Initiative. Arthritis Res Ther 2013;15:R106-R117.

4. Ghosh P, Guidolin D: Potential mechanism of action of intraarticular hyaluronan therapy in osteoarthritis: Are the effects molecular weight dependent? Semin Arthritis Rheum 2002;32:10-37.

5. Bannuru RR, Natov NS, Dasi UR, Schmid CH, McAlindon TE: Therapeutic trajectory following intra-articular hyaluronic acid injection in knee osteoarthritis-Meta-analysis. Osteoarthritis Cartilage 2011;19:611-619.

6. American College of Rheumatology Subcommittee on Osteoarthritis Guidelines: Recommendations for the medical management of osteoarthritis of the hip and knee. Arthritis Rheum 2000; 43:1905-1915.

7. Sawitzke AD, Shi H, Finco MF, et al.: The effect of glucosamine and/or chondroitin sulfate on the progression of knee osteoarthritis: A report from the glucosamine/chondroitin arthritis intervention trial. Arthritis Rheum 2008;58:3183-3191.

8. Black C, Clar C, Henderson R, et al.: The clinical effectiveness of glucosamine and chondroitin supplements in slowing or arresting progression of osteoarthritis of the knee: A systemic review and economic evaluation. Health Technol Assess 2009;13:1-148.

9. Walz CP, Barry AR, Koshman SL: Omega-3 polyunsaturated fatty acid supplementation in the prevention of cardiovascular disease. Can Pharm J 2016;149:166-173.

10. Kremer JM, Jubiz W, Michalek A, et al.: Fish-oil fatty acid supplementation in active rheumatoid arthritis. A double-blinded, controlled, crossover study. Ann Intern Med 1987;106:497-503.

11. van der Tempel H, Tulleken JE, Limburg PC, Muskiet FA, van Rijswijk MH: Effects of fish oil supplementation in rheumatoid arthritis. Ann Rheum Dis 1990;49:76-80.

12. Borow KM, Nelson JR, Mason RP: Biologic plausibility, cellular effects, and molecular mechanisms of eicosapentaenoic acid (EPA) in atherosclerosis. Atherosclerosis 2015;242:357-366. 
13. Im DS: Omega-3 fatty acids in anti-inflammation (proresulution) and GPCRs. Prog Lipid Res 2012;51:232-237.

14. Wann AK, Mistry J, Blain EJ, Michael-Titus AT, Knight MM: Eicosapentaenoic acid and docosahexaenoic acid reduce interleukin- $1 \beta$-mediated cartilage degradation. Arthritis Res Ther 2010;12:R207-R215.

15. Connor KM, SanGiovanni JP, Lofquist C, et al.: Increased dietary intake of omega-3-polyunsaturated fatty acids reduces pathological retinal angiogenesis. Nat Med 2007;13:868-873.

16. Lim JY, Park CK, Hwang SW: Biological roles of resolvins and related substances in the resolution of pain. Biomed Res Int 2015;2015:830930.

17. Jackson H, Braun CL, Ernst H: The chemistry of novel xanthophyll carotenoids. Am J Cardiol 2008;101:50D-57D.

18. Kurashige M, Okimasu E, Inoue M, Utsumi K: Inhibition of oxidative injury of biological membranes by astaxanthin. Physiol Chem Phys Med NMR 1990;22:27-38.

19. Ohgami K, Shiratori K, Kotake S, et al.: Effects of astaxanthin on lipopolysaccharide-induced inflammation in vitro and in vivo. Invest Ophthalmol Vis Sci 2003;44:2694-2701.

20. Speranza L, Pesce M, Patruno A, et al.: Astaxanthin treatment reduced oxidative induced pro-inflammatory cytokines secretion in U937. Mar Drugs 2012;10:890-899.

21. Suzuki Y, Ohgami K, Shiratori K, et al.: Suppressive effects of astaxanthin against rat endotoxin-induced uveitis by inhibiting the NF-kappaB signaling pathway. Exp Eye Res 2006;82: 275-281.

22. Park JS, Chyun JH, Kim YK, Line LL, Chew BP: Astaxanthin decreased oxidative stress and inflammation and enhanced immune response in humans. Nutr Metab 2010;7:18-27.

23. Kamath BS, Srikanta BM, Dharmesh SM, Sarada R, Ravishankar GA: Ulcer preventive and antioxidative properties of astaxanthin from Haematococcus pluvialis. Eur J Pharmacol 2008;590: 387-395.

24. Spiller GA, Dewell A: Safety of an astaxanthin-rch Haematococcus pluvialis algal extract: A randomized clinical trial. J Med Food 2003;6:51-56.

25. Chen WP, Xiong Y, Shi YX, et al.: Astaxanthin reduces matrix metalloproteinase expression in human chondrocytes. Int Immunopharmacol 2014;19:174-177.

26. Kataoka Y, Ariyoshi W, Okinaga T, et al.: Mechanisms involved in suppression of ADAMTS4 expression in synoviocytes by high molecular weight hyaluronic acid. Biochem Biophys Res Commun 2013;432:580-585.

27. Guerra D, Frizziero L, Losi M, et al.: Ultrastructural identification of a membrane-like structure on the surface of normal articular cartilage. J Submicrosc Cytol Pathol 1996;28:385-393.

28. Guidolin DD, Ronchetti IP, Lini E, Guerra D, Frizziero L: Morphological analysis of articular cartilage biopsies from a randomized, clinical study comparing the effects of 500-730 kDa sodium hyaluronate (Hyalgan) and methylprednisolone acetate on primary osteoarthritis of the knee. Osteoarthritis Cartilage 2001;9:371-380.

29. Moreland LW: Intra-articular hyaluronan (hyaluronic acid) and hylans for the treatment of osteoarthritis: Mechanisms of action. Arthritis Res Ther 2003;5:54-67.

30. Zhou PH, Liu SQ, Peng H: The effect of hyaluronic acid on IL1 beta-induced chondrocyte apoptosis in a rat model of osteoarthritis. J Orthop Res 2008;26:1643-1648.
31. John AM, Rudi EM, Stephen HW, Swati ST, Lingan R: Composition and method to alleviate joint pain. U.S. Patent 12/ 840,372. July 21, 2010.

32. John AM, Rudi EM, W. Stephen H, Swati ST, Lingan R: Composition and method to alleviate joint pain using algae based oils. U.S. Patent US 13/914,725. October 31, 2013.

33. Chen WT, Mahmood U, Weissleder R, Tung CH: Arthritis imaging using a near infrared, fluorescence folate-targeted probe. Arthritis Res Ther 2005;7:R310-R317.

34. Nakayama M, Niki Y, Kawasaki T, et al.: Enhanced susceptibility to lipopolysaccharide-induced arthritis and endotoxin shock in interleukin-32 alpha transgenic mice through induction of tumor necrosis factor alpha. Arthritis Res Ther 2012;14: R120-R130.

35. Akira S, Uematsu S, Takeuchi O: Pathogen recognition and innate immunity. Cell 2006;124:783-801.

36. Kaisho T, Akira S: Dendritic-cell function in toll-like receptorand MyD88-knockout mice. Trends Immunol 2001;22:78-83.

37. Kawai T, Akira S: The role of pattern-recognition receptors in innate immunity: Update on Toll-like receptors. Nat Immunol 2010;11:373-384.

38. Venkatesha SH, Dudics S, Acharya B, Moudgil KD: Cytokinemodulating strategies and newer cytokine targets for arthritis therapy. Int J Mol Sci 2015;16:887-906.

39. Liu Z, Fan Y, Wang Y, et al.: Dipyrithione inhibits lipopolysaccharide-induced iNOS and COX-2 up-regulation in macrophages and protects against endotoxic shock in mice. FEBS Lett 2008;582:1643-1650.

40. Lee JA, Song HY, Ju SM, et al.: Differential regulation of inducible nitric oxide synthase and cyclooxygenase-2 expression by superoxide dismutase in lipopolysaccharide stimulated RAW 264.7 cells. Exp Mol Med 2009;41:629-637.

41. Burrage PS, Mix KS, Brinckerhoff CE: Matrix metalloproteinases: Role in arthritis. Front Biosci 2006;11:529-543.

42. Yusuf E, Kortekaas MC, Watt I, Huizinga TW, Kloppenburg M: Do knee abnormalities visualized on MRI explain knee pain in knee osteoarthritis? A systematic review. Ann Rheum Dis 2011;70:60-67.

43. Berenbaum F: Osteoarthritis as an inflammatory disease (osteoarthritis is not osteoarthrosis!) Osteoarthritis Cartilage 2013;21: $16-21$.

44. Wieland HA, Michaelis M, Kirschbaum BJ, Rudolphi KA: Osteoarthritis-An untreatable disease? Nat Rev Drug Discov 2005;4:331-344.

45. Tedeschi SK, Costenbader KH: Is there a role for diet in the therapy of rheumatoid arthritis? Curr Rheumatol Rep 2016;18: 23-31.

46. Opp MR, Smith EM, Hughes TK, Jr: Interleukin-10 (cytokine synthesis inhibitory factor) acts in the central nervous system of rats to reduce sleep. $J$ Neuroimmunol 1995;60:165-168.

47. Kristiansen OP, Mandrup-Poulsen T: Interleukin-6 and diabetes: The good, the bad, or the indifferent? Diabetes 2005;54: S114-S124.

48. Locksley RM, Killeen N, Lenardo MJ: The TNF and TNF receptor superfamilies: Integrating mammalian biology. Cell 2001; 104:487-501.

49. Dowlati Y, Herrmann N, Swardfager W, et al: : A meta-analysis of cytokines in major depression. Biol Psychiatry 2010;67: $446-457$. 
50. Brynskov J, Foegh P, Pedersen G, et al.: Tumour necrosis factor alpha converting enzyme (TACE) activity in the colonic mucosa of patients with inflammatory bowel disease. Gut 2002;51: 37-43.

51. Tanabe K, Matsushima-Nishiwaki R, Yamaguchi S, et al.: Mechanisms of tumor necrosis factor-a-induced interleukin-6 synthesis in glioma cells. J Neuroinflammation 2010;7:16-23.

52. Nishimoto N: Interleukin-6 in rheumatoid arthritis. Curr Opin Rheumatol 2006;18:277-281.

53. Chen CC, Sun YT, Chen JJ, Chiu KT: TNF-alpha-Induced cyclooxygenase-2 expression in human lung epithelial cells: Involvement of the phospholipase C-gamma 2, protein kinase C-alpha, tyrosine kinase, NF-kappa B-inducing kinase, and
I-kappa B kinase 1/2 Pathway. J Immunol 2000;165:27192728.

54. Molina-Holgado E, Ortiz S, Molina-Holgado F, Guaza C: Induction of COX-2 and PGE2 biosynthesis by IL-1b is mediated by $\mathrm{PKC}$ and mitogen-activated protein kinases in murine astrocytes. Br J Pharmacol 2000;131:152-159.

55. Sadowski T, Steinmeyer J: Effects of non-steroidal antiinflammatory drugs and dexamethasone on the activity and expression of matrix metalloproteinase-1, matrix metalloproteinase-3 and tissue inhibitor of metalloproteinases- 1 by bovine articular chondrocytes. Osteoarthritis Cartilage 2001;9:407-415.

56. Dingle JT: The effects of NSAID on the matrix of human articular cartilages. Z Rheumatol 1999;58:125-129. 